\title{
CONTEXTUALIZANDO EL ARTE NANBAN EN NAGASAKI, LA CIUDAD MENOS JAPONESA DE JAPÓN
}

\author{
JOSEPH CABEZA-LAINEZ. \\ Universidad de Sevilla \\ INMACULADA RODRÍGUEZ-CUNILL \\ Universidad de Sevilla
}

\section{Resumen}

En el presente texto los autores se interrogan sobre las razones y la función territorial y urbana de la singular Nagasaki. Este enclave fue ibérico en origen y fundación, pero desarrollado posteriormente al modo nipón hasta nuestros días. El secular aislamiento del archipiélago japonés, llamado por muchos sakoku 鎖国, que viene a significar "país encadenado", implica que las influencias occidentales no sean muy profundas ni duraderas y de ahí la originalidad de este enclave asiático. Sin embargo, es en el arte Nanban donde la efervescencia generada por el encuentro cultural entre oriente y occidente se plasma en objetos artísticos de gran belleza y que son a la vez reveladores documentos históricos.

Nagasaki, arte Nanban, jesuitas

\section{Palabras clave}

\section{CONTEXTUALIZING NANBAN ART IN NAGASAKI, THE LEAST JAPANESE CITY IN JAPAN}

\begin{abstract}
In this text, the authors question the territorial and urban reasons and function of the singular Nagasaki. This enclave was Iberian in origin and foundation, but later developed in Japanese mode until today. The secular isolation of the Japanese archipelago, called by many sakoku 鎖 国, which can be translated as "enchained country", implies that Western influences are not very deep or lasting and hence the originality of this Asian enclave.

However, it is in Nanban art where the effervescence generated by the cultural encounter between East and West is reflected in artistic objects of great beauty that become revealing historical documents at the same time.
\end{abstract}

Nagasaki, Nanban Art, Jesuits

$$
\text { Key words }
$$




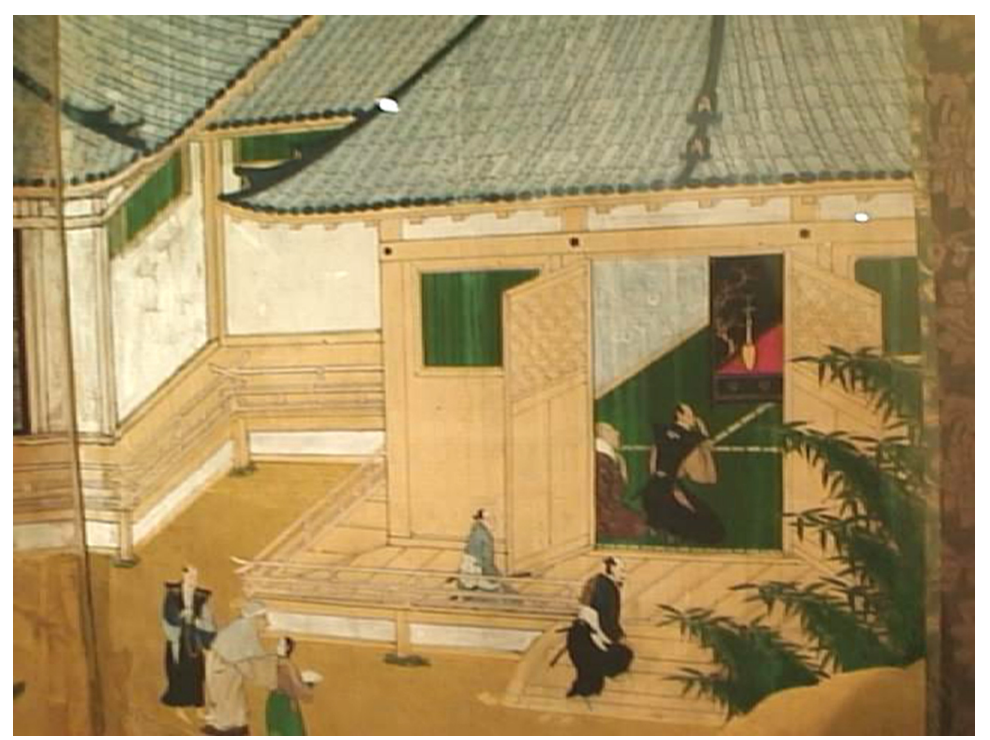

Fig. 1. Biombo Nanban (de los "bárbaros del sur"). Siglo XVII. Fragmento que muestra un templo japonés con sus principales características para el culto. Fuente: Museu Nacional da Arte Antiga. Lisboa

\section{Introducción}

En las guerras del Peloponeso, el Almirante Nicias intenta disuadir a los atenienses de la conquista de Siracusa (la actual Sicilia) y lo hace con una persuasiva expresión que ha perdurado hasta hoy:

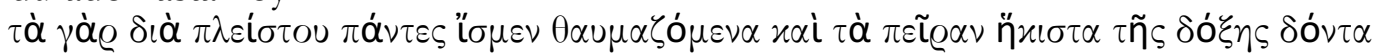

Pues sabido es por todos que lo más lejano resulta portentoso, así como aquello de lo que menos pruebas existen.

Lo lejano y lo improbable es lo que induce a maravilla, de ahí la fascinación por Asia y por un país tan misterioso como inexpugnable, Japón, en el que por una serie de oportunidades históricas los ibéricos llegaron a atisbar aquello alejado y portentoso, y cuyo contexto dio frutos artísticos en el arte Nanban.

\section{Contexto cultural e histórico de la fundación}

Tras una década de prospecciones, los lusitanos hallaron en la profunda bahía de Nagasaki el lugar ideal para establecer el extremo de la ruta comercial sino-japonesa que habían explorado desde mediados del siglo XVI y que del lado chino se asentaría en Macao en 1557.

Allí se establecieron definitivamente en 1570, y en la primavera siguiente se dotaron las "cuarteladas" y se trasladaron las primeras familias japonesas. Como es característico de la expansión portuguesa, el lugar fue escogido en función de la red marítima que iba a nutrir, como si se tratara de una factoría mercantil.

Esta bahía profunda, protegida por un largo promontorio al que debe su nombre (saki= cabo, promontorio), estaba enclavada en un terreno montañoso donde no debería levantarse, como seguidamente discutiremos, una ciudad de factura japonesa.

\section{Diferencias entre la ciudad arcaica de asia oriental y la de occidente}

La ciudad nipónica se basa en el modelo chino del Feng Shui. Se levantaba por lo general en terrenos de poca pendiente con una disposición en damero, estando protegida en su 


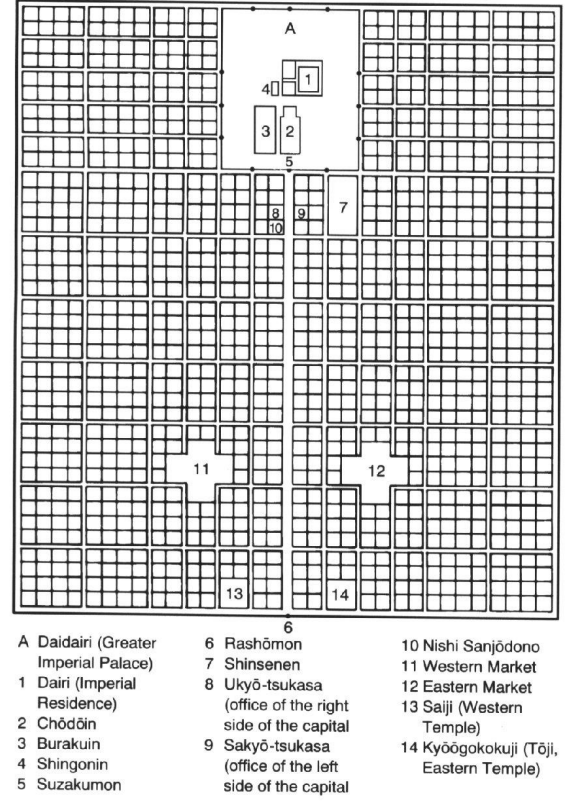

106. Plan of Heiankyō (Kyoto) as originally laid out
Fig. 2. Plano de Heiankyô (Kyôtô) en su fundación en el año 795. La calle principal, llamada avenida del Fénix Rojo 朱雀 está orientada exactamente en dirección Norte-Sur. Fuente: Penelope Mason. History of Japanese Art

estribación noreste de las influencias nocivas mediante empinadas montañas donde surgen pagodas y templos con función apotropaica.

Lo que conocemos sobre las arcanas ciudades de origen védico que siguen el Shilpa Shastra, (Tratado de los asentamientos, que incluye manuales de escultura e iconografía hindúes) u otra narrativa ligada al Vastu (que en Sri Lanka se llama Nekat), también se verificaba en las primitivas urbes japonesas, y revela una relación entre la sabiduría del Shastra y la geomancia usada en China, el imperio del centro. El antiguo emporio de Kyôtô, anteriormente llamado Heian, disponía de una trama muy elaborada con retículas de calles y bulevares. Sin embargo, aquí no se dispondrían plazas sino más bien amplias avenidas ceremoniales donde congregar a las muchedumbres.

Los lugares de culto y los edificios oficiales se construían a lo largo de bulevares, en vez de estar concentrados en un núcleo que rodea a una plaza pública o de proporcionar algún otro tipo de centralidad a la urbe. Este modelo urbano es diametralmente opuesto al que se recoge en los tratadistas romanos, tales como Vitrubio, quien tanta influencia tendría al adaptarse sus teorías en las leyes de Indias para el asentamiento de ciudades en el Nuevo Mundo.

De la misma manera en que en la antigua India, la construcción de un templo proporcionaba a un rey o noble, un reconocimiento perdurable, y curiosamente el perdón por todo crimen, incluyendo el asesinato de un brahmán o sacerdote. No obstante, esta inmortalidad resultaba paradójica puesto que según las escrituras del Shilpa Prakasha, "todo se desvanece con el tiempo, y sólo los monumentos duran para siempre"”.

Una posible razón para estas disposiciones urbanas era la conveniencia de las mismas durante los festivales, que en el Este principalmente toman la forma de procesiones más que asambleas de masa. Las calles más importantes en Kyoto 京都, sin embargo, no funcionaban como parte de la vida comunitaria de las personas. Estaban pensadas para la circulación en carruajes y para las procesiones festivas en unas áreas de ostentación de poder por parte de los regentes y los aristócratas.

También podemos encontrar justificaciones para este comportamiento, y es que los edificios de la oligarquía japonesa y china siempre han estado vedados para los comunes, lo que provoca que determinados rasgos sociales como las escaleras imperiales, balcones y

${ }^{1}$ Kaulācāra, 1966: 62. Trad. de los autores. 


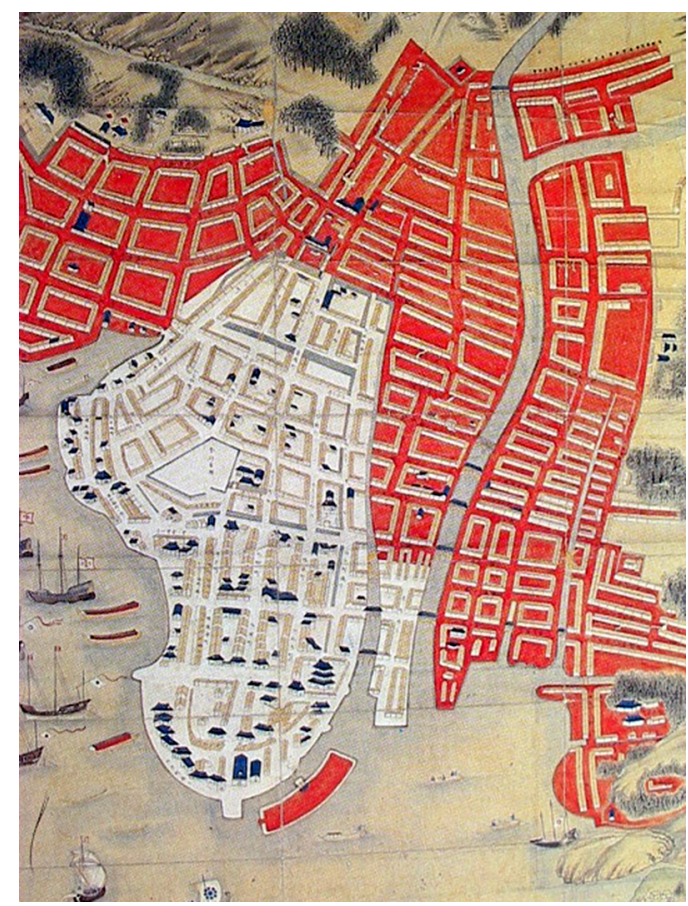

Fig. 3. Mapa Kan'Ei de Nagasaki (1637). Autor desconocido. Fuente: Gunn, G. C. (2017). World Trade Systems of the East and West. World Trade Systems of the East and West. https://doi.org/10.1163/97890 $\underline{04358560}$

balaustradas o hasta fuentes y jardines ornamentales precediendo a los palacios, sean relativamente escasos en Asia oriental.

Las avenidas a las que hacemos referencia estaban flanqueadas por las casas de los más acaudalados en una disposición diseñada para atraer habitantes a la ciudad a través del comercio, los ritos religiosos y el despliegue de autoridad.

Las calles estrechas, los callejones y los pasajes, por otro lado, eran una parte integral del estilo de vida del populacho. Los callejones que se entrelazaban en la típica disposición con entradas angostas como en el distrito de los tejedores de Nishi-jin o Ponto-chô (del portugués "ponte", puente) en Kyôtô, eran más bien callejones y, no importantes arterias de tráfico.

Las principales vías marcaban claramente las fronteras de los diferentes distritos o comunidades, mientras que las calles pequeñas se entrelazaban a lo largo de cada distrito y a veces no llevan a ninguna parte en una suerte de cul-de-sac. Las casas se alineaban en una callejuela formando una vecindad íntimamente relacionada. Estas entidades menores, frecuentemente tienen menos de 3 metros de ancho (fig. 1).

La ciudad con sus casas de madera ofrecía muy fácil acceso. Las fachadas provistas de ventanas con celosía de bambú hacían que las casas fueran más bien una parte de la calle que un refugio frente a sus bulliciosas actividades. Este sería un punto de origen de las llamadas machiya, prácticamente una mezcla entre zonas residenciales y talleres de artesanía o comercios. En las tardes de verano estas barriadas se poblaban con gente que buscaba alivio para el creciente calor. Las personas charlaban desde la ventana con rejas de bambú (llamadas sudare), y las habitaciones que miraban a la calle ocasionalmente hacían las veces de tiendas o talleres.

Mientras tanto, las avenidas principales servían para las formalidades, los festivales o las manifestaciones, pero las calles menores constituían áreas comunes para la gente del pueblo.

A título explicativo, podemos afirmar, que en las ciudades que siguen las prescripciones del Feng-Shui, tales como Heian-kyô 平安京 (Kyôtô), Nara o Beijing, la orientación favorable se encuentra dirigida hacia el Sur, protegida del Norte (Ki-mon 鬼門 o puerta del demonio) por montañas y defendida también por el Este y el Oeste mediante lagos o colinas (El Dragón Azul al Este 青龍 y el Tigre Blanco al Oeste 白虎 ), es decir hay una presencia constante de los llamados cuatro guardianes mitológicos o Shitenno.

Como hemos comentado, la plaza no surge en estas latitudes y toma protagonismo la calle procesional. El concepto de espacio público se ve así alterado, pues la calle en Japón y China 


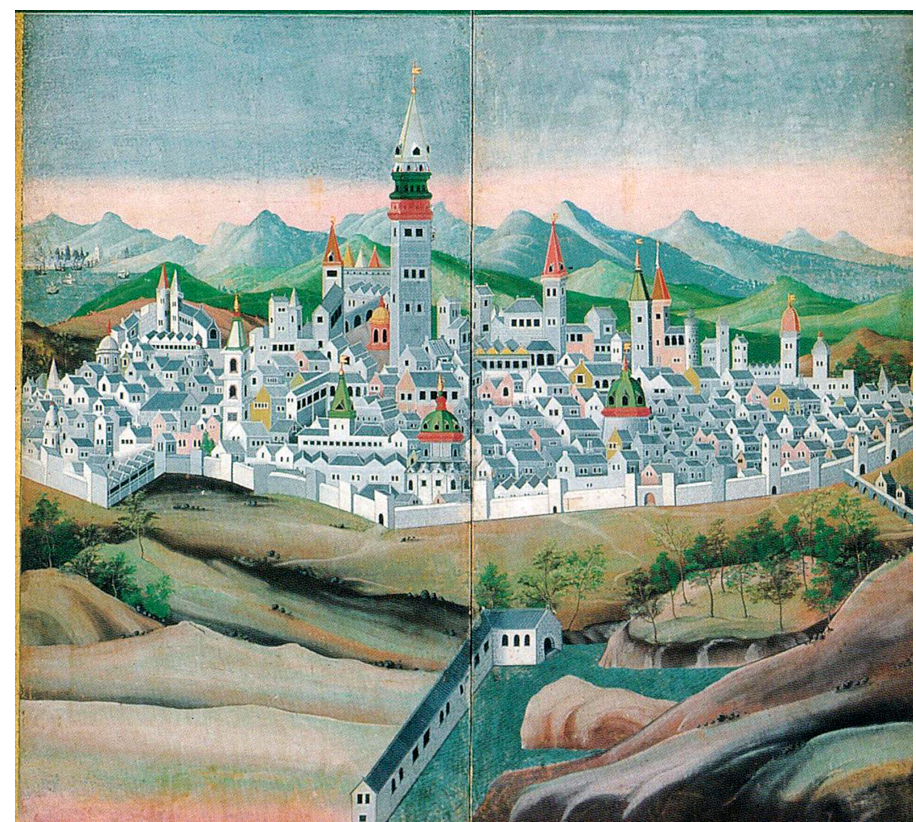

Fig. 4. Representación japonesa de Sevilla ca. 1600. Fuente: colección Iqeda del Museo de Kobe.

pertenecía como hemos visto a los espacios colindantes y solamente era prestada para circular por ella. Esta situación no cambió hasta 1600, año en que el shôgun Hideyoshi eximió finalmente de pagar impuestos por el disfrute de la calle. Ello explica incluso en la actualidad lo azaroso del viario en las urbes nipónicas (fig. 2).

\section{Características fundacionales definidas por el mestizaje y la inculturación}

Omura Sumitada, el principal daimyô o señor feudal de quien tengamos constancia, cedió el terreno para la construcción de la ciudad de Nagasaki en la zona del puerto. Todavía intentó de algún modo mantener la tradición: procedió a realizar terraplenes y mandó abrir una calle principal cortada por varias perpendiculares. Este pequeño terreno allanado y vagamente aterrazado en bancales, quizá con idea de favorecer algunos cultivos, pronto se mostró insuficiente para albergar a todos aquellos que venían a establecerse en Nagasaki, bien porque se dedicaban al comercio, bien porque eran cristianos imposibilitados para vivir libremente su fe en las tierras de origen, u otros diversos motivos.

Así, bien pronto Nagasaki ganó un perfil característico desde el punto de vista del urbanismo japonés, que nos es más familiar de comprender siguiendo los patrones lusitanos de ciudad, pues el caserío comenzó a ascender por los escarpes de la colina, disponiéndose a lo largo de vías sinuosas, abiertas según el terreno lo permitía y no siguiendo un modelo sistemático.

La ciudad adquirió ciertos rasgos característicos que la distinguen incluso hoy día de cualquier otro conglomerado urbano nipónico. Las distintas manzanas o cuadrantes interiores de la ciudad no están colmatadas (fig. 3), sino que presentan abundantes vacíos a manera de corrales o patios semi-abiertos. Puede decirse pues que éste fue otro efecto duradero de la relación ibérico-japonesa y sin duda uno de los más sobresalientes.

Si desde el punto de vista del modelo de urbanismo, incluso ahora podemos decir que Nagasaki es la ciudad menos japonesa de Japón, hace cuatro siglos existían muchas otras características que la distinguían en el contexto de la civilización nipónica. En todo caso no podemos llegar a hablar de un urbanismo a la manera barroca totalmente desarrollado, como en la ciudad que se nos dibuja en El mundo por de dentro de Francisco de Quevedo, con su 


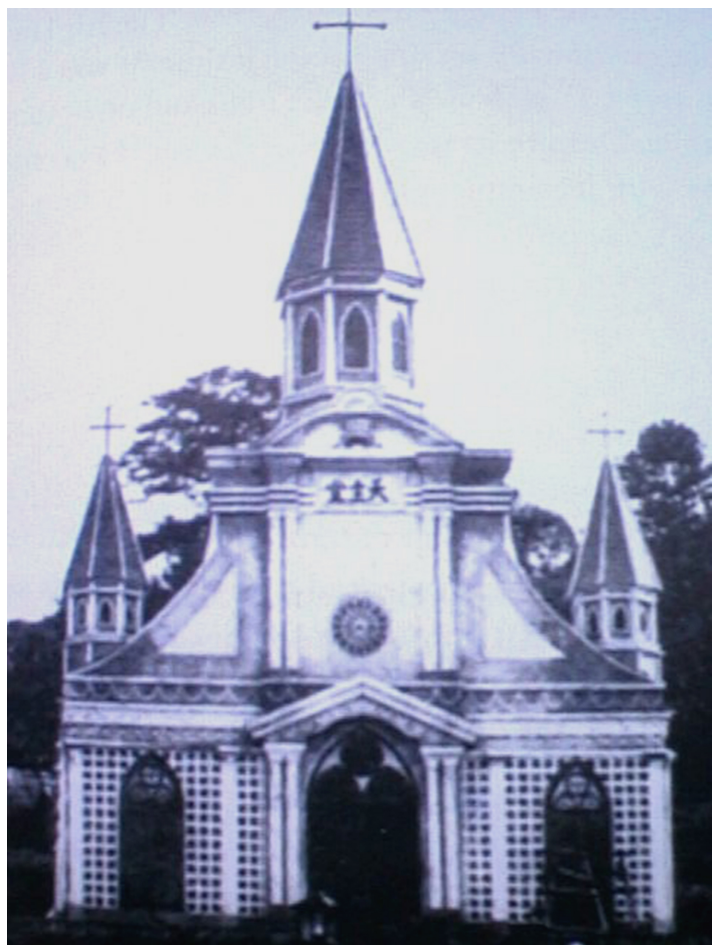

Fig. 5. La catedral (fachada original) de Oura en Nagasaki (ca. 1870). Fuente: Museo de Historia de Nagasaki

famosa calle de la hipocresía, la de la ira, la calle mayor de mundo, etc.; pero sí de intenciones que de una manera u otra fueron cristalizando tal como podemos apreciar en maravillosas representaciones pictóricas japonesas de las principales ciudades del planeta (a saber, Istanbul, Lisboa, Roma y Sevilla) que llegaron a ser extraordinariamente populares. Ilustramos esta idea con la representación de la capital de mundo, Sevilla (fig. 4).

\section{Hábitos lingüísticos, costumbres y conflictos religiosos}

Respecto a las influencias culturales, más allá de variados hábitos típicos de los occidentales que fueran gradualmente adoptados por sus habitantes, es fundamental considerar que la ciudad era habitada en su gran mayoría, cristianos y hablaban una lengua mucho más marcada por los extranjerismos que en el resto del país: las consabidas palabras japonesas, pan, tabako, tempura, compeito (confite) o marmelo (membrillo) por citar muy pocas, son buena muestra de estos préstamos lingüísticos. Las influencias sobre el vestido, los ornamentos el mobiliario o la alimentación fueron también notables, hasta el punto de llegar a la Corte Imperial japonesa y a los oídos del Shogun.

Nagasaki fue como podemos comprender, habitada desde su fundación por cristianos, muchos de los cuales eran perseguidos en sus lugares de origen, por lo que el pueblo consolidó esta especificidad (fig. 5). Las cartas de los jesuitas refieren a menudo el hecho de que la ciudad estaba habitada por más niños que en otras partes, pues no se practicaba el infanticidio que era entonces, práctica corriente entre la mayoría de clases sociales.

Hasta el colapso de la casa de Bungo a manos de los Shimazu de Satsuma, las principales instituciones de la misión jesuítica estaban situadas en Funai o en Utsuki bajo la protección de Otomo Yoshishige. Fue precisamente en Funai, la capital de este feudo, donde la Santa Sede fijó en febrero de 1588 la primera diócesis nipónica²

Mientras tanto, cuando se tomaba esta decisión en Roma, la situación se alteró significativamente en Japón como hemos tratado en otros artículos y el principal centro de la compañía pasó a ser Nagasaki, donde residió Luis Cerqueira, el único obispo que ejerció

\footnotetext{
2 Bailey, 1999: 123.
} 
Fig 6. Plano de la Ciudad de Nara. Fuente: Penelope Mason. History of Japanese Art.

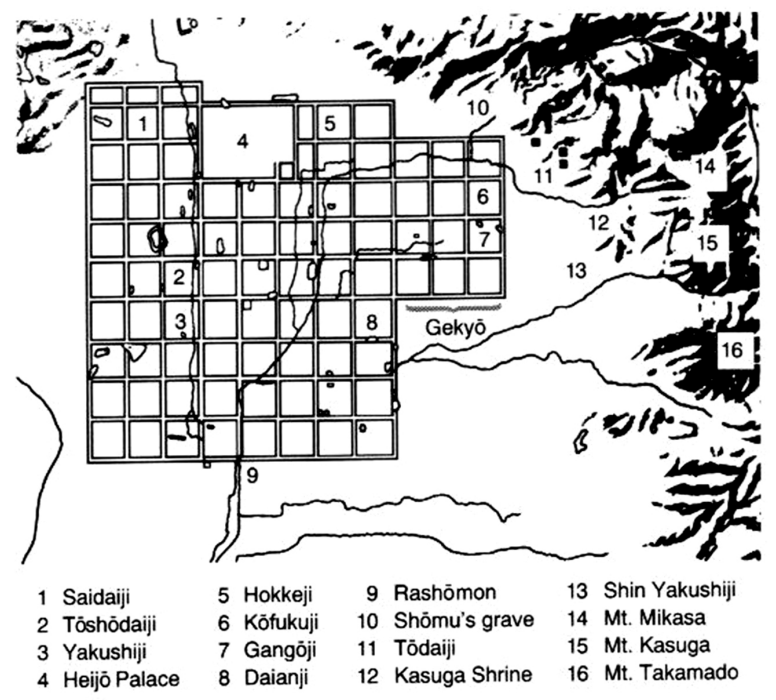

78. Map of Heijōkyō (Nara)

una acción pastoral continuada en Japón en la época Nanban hasta su fallecimiento en 1614. Precisamente a su llegada en 1598, le fue prohibido asistir a la traumática ejecución de los llamados Mártires Japoneses en la colina de Nishizaka, donde hoy se encuentra un conocido museo que da buena cuenta de estos sucesos.

En la última parte de su historia de Japón, al relatar acontecimientos relativos a 1592, Fróis afirma que: "en todo Japón no hay otro lugar donde haya comodidades para que se recobren los débiles y enfermos como en Nagasaki, donde también por la acción de los portugueses que allí habitan, se encuentran algunas medicinas y comodidades apropiadas para nuestra naturaleza occidental"3.

El establecimiento de varios mercaderes lusos y su casamiento con mujeres japonesas, lo que sucedió prácticamente desde la fundación, hicieron a esta ciudad todavía más similar a otras que los portugueses habían creado u ocupado en tres continentes, con la aparición de una generación de luso-japoneses.

La construcción de iglesias resultó característica en este período pues como expone acertadamente Lefevre: “¿Qué quedaría de una ideología religiosa...si no se basase en los lugares y sus nombres? ¿Qué quedaría de la Iglesia si no hubiese iglesias? La respuesta es Nada, ya que la Iglesia no garantiza ni puede garantizar su supervivencia de otro modo"

\section{Oposición a las creencias geománticas}

Para los antiguos chinos y los indios, el verdadero símbolo de una ciudad fueron sus murallas y puertas de entrada, a menudo construidas antes de ejecutar los propios palacios o las casas. Así los principales caracteres o logogramas antiguos empleados para referirse a las ciudades o la construcción de ciudades fueron: Cheng 城 (Japonés: Sei, Jô), Du 都 (To), y Jing 京 (Kyô). Es fácil comprobar como muchos de ellos perviven en la actual terminología, siempre relacionados con las cuatro direcciones cardinales asociadas a los guardianes mitológicos. Ejemplos típicos Kyoto 京都, Tokio東京, Beijing 北京, Nanjing 南京o Chengdu 成都.

La construcción y guarda de las puertas está dotada en el mundo de Asia Oriental de una enorme significación y misticismo. En sánscrito se las conoce como toranas, de donde derivan las palabras inglesa y alemana door y tor y, pero también el japonés torii 鳥居, que es una suerte

\footnotetext{
${ }^{3}$ Fróis, 1993: 90.

${ }^{4}$ Lefevre, 1991: 44.
} 


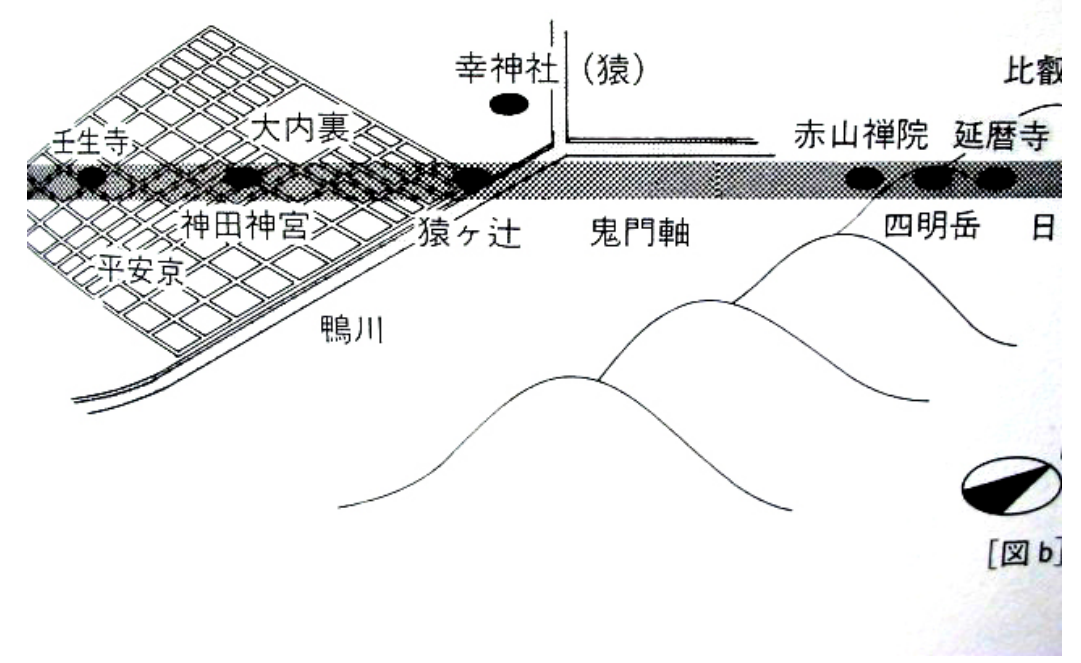

Fig 7. Gráfico japonés que explica la dirección nefasta del Kimon 鬼門aplicada a la retícula de Heian-Kyo (actual Kyoto). Fuente: Cabeza Lainez, J. M. La Visión y la Voz: arte, ciudad y cultura en Asia Oriental (p.190).

de portal en el que el sol queda posado al amanecer como si de un gallo se tratara y de ahí la polisemia con la voz torii que también designa al ave.

A menudo la ceremonia de fundación de una ciudad incluía la erección de los portales a los que se dotaba de defensas militares, pero también espirituales al convocar en ellas a combatientes fallecidos cuyos huesos calcinados se fertilizaban para la ocasión con la sangre de los sacrificios de animales.

El Zhuangzi ironiza en algunos pasajes sobre la condición de seguridad que confería a un aprendiz el ser nombrado guardián de la puerta pues tal estatus obligaba al mismo tiempo a recibir cierta leve mutilación en los miembros inferiores a fin de dificultar la huida en caso de atacantes.

En el caso de Japón raramente se rodeaba a las ciudades con bastiones, aunque hemos visitado restos arqueológicos de estructuras de tierra compactada que, al parecer envolvían a la antigua Nara 平城, cuyo nombre arcaico menciona la palabra castillo (Heijô). Sin embargo, los principios del Feng-Shui se aplicaron casi del mismo modo que en China e incluso hoy perviven muchos vestigios de esta actitud. Por ejemplo: se da un abundante sincretismo entre creencias primigenias, ligadas al Daoismo o al Shintoismo, y el buddhismo posterior, y eso provoca que los animales mitológicos de las cuatro direcciones se transformen en reyes protectores del buddhismo (los famosos Jikokuten 持国天 en la dirección Este, Zochoten 増 長天 hacia el sur, Komokuten 広目天 por el oeste, y Tamonten 多聞天 al norte, en sánscrito se llaman चतुर्महाराज caturmahäräja).

Una de las estructuras más famosas en este sentido, que hemos tenido ocasión de frecuentar, es el complejo de Kurama-dera al noreste de Kyôtô, el cual, de acuerdo con las inscripciones allí presentes, debería de proteger la ciudad de la llegada de las plagas y fuerzas malignas que poblaban el hemisferio correspondiente.

Las llamadas direcciones privilegiadas u "octavas del aire" fueron un hecho admitido en el antiguo Japón y existió la práctica del Katatagae que designa el acto de evitar una dirección desafortunada. El maestro de adivinaciones informaba sobre las direcciones bloqueadas por 


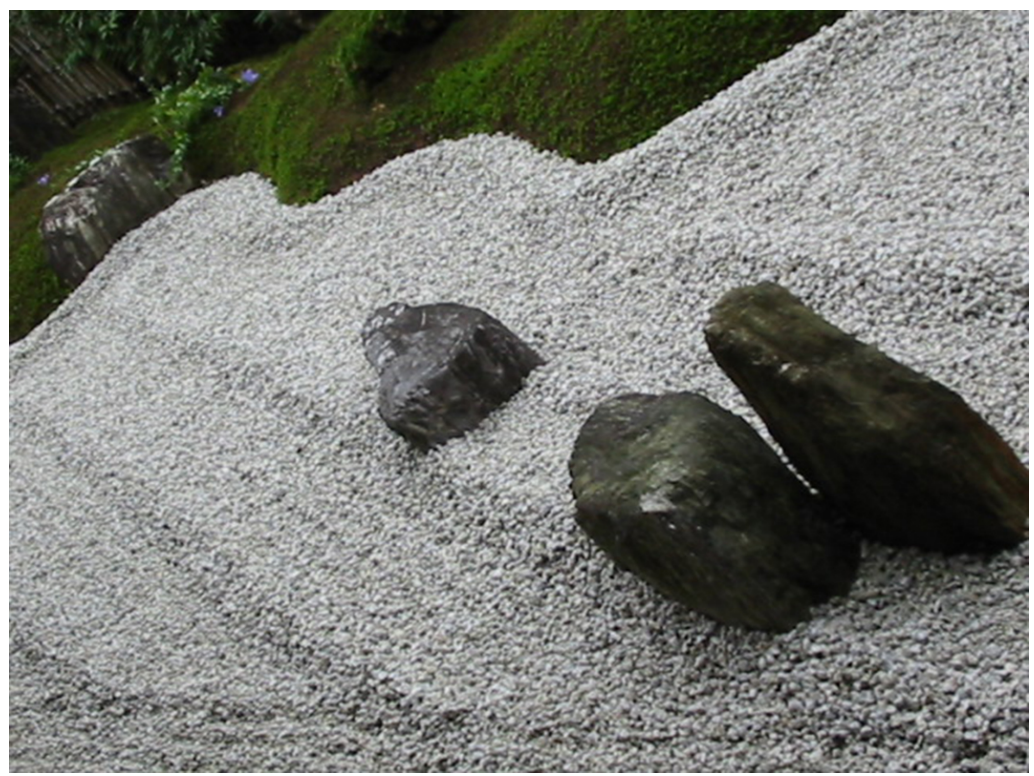

Fig. 8. El llamado "jardín de la cruz" obra del señor feudal Omura Sumitada que se convirtió al cristianismo en la era Muromachi. Las piedras intentan dibujar una cruz en vista oblicua. Fuente: Joseph Cabeza-Lainez

las deidades invisibles y dinámicas, centrales en la creencia de la época. Las precauciones eran mayores durante los cambios de estación. Una persona que estuviera pasando por una situación de katatagae merecía ser recibida con deferencia y consideración.

En el Makura no Sôshi 枕の草紙 (Libro de la almohada), diario íntimo fechado en el 1002, Sei Shōnagon refleja la importancia de las direcciones y el mundo espiritual: "Una ha ido a la casa de un amigo para evitar una dirección desafortunada pero no se hace nada para distraernos; si esto sucede en el momento del cambio de las estaciones, es todavía más descortés"

Tanto en la ciudad de Nara (fig. 6) como en Kyoto (fig. 7) se explican los sesgos nefastos dependiendo de las direcciones.

\section{Significado político y funcional de la llegada de los europeos. Nanban 南蛮 a partir de 1530}

Las reglas de disposición de asentamientos urbanos se mantuvieron con una evolución relativamente pequeña. Hoy son visibles en importantes capitales existentes (Kyôtô) o desaparecidas (Hiraizumi) y no se han documentado grandes contactos con otras regiones extranjeras aparte de China hasta que en el horizonte apareció una importante fuerza. Los imperios marítimos ibéricos finalmente habían encontrado una ruta hacia el Oriente insistentemente buscado desde Cristóbal Colón y estaban suficientemente preparados para explotarla.

Este factor nuevo y sin precedentes produjo al principio desequilibrios de toda índole y posteriormente oportunidades para el comercio y el intercambio de ideas que a su vez resultaron necesarias para permanecer en el poder político y obtener mayor riqueza.

Por lo tanto, el principal resultado del periodo fue la ciudad "cristianizada". En este caso único, pareció existir una dilatada decisión tanto por parte de los Jesuitas y de las autoridades

\footnotetext{
5 Shōnagon (1971): 56.
} 
Fig. 9. La cruz muy engalanada encima de una iglesia cristiana de la época. La iglesia es un templo japonés reconvertido. Fuente: Museo de Historia de Nagasaki Fuente: Cabeza Lainez, J. M. La Visión y la Voz: arte, ciudad y cultura en Asia Oriental (p.190).

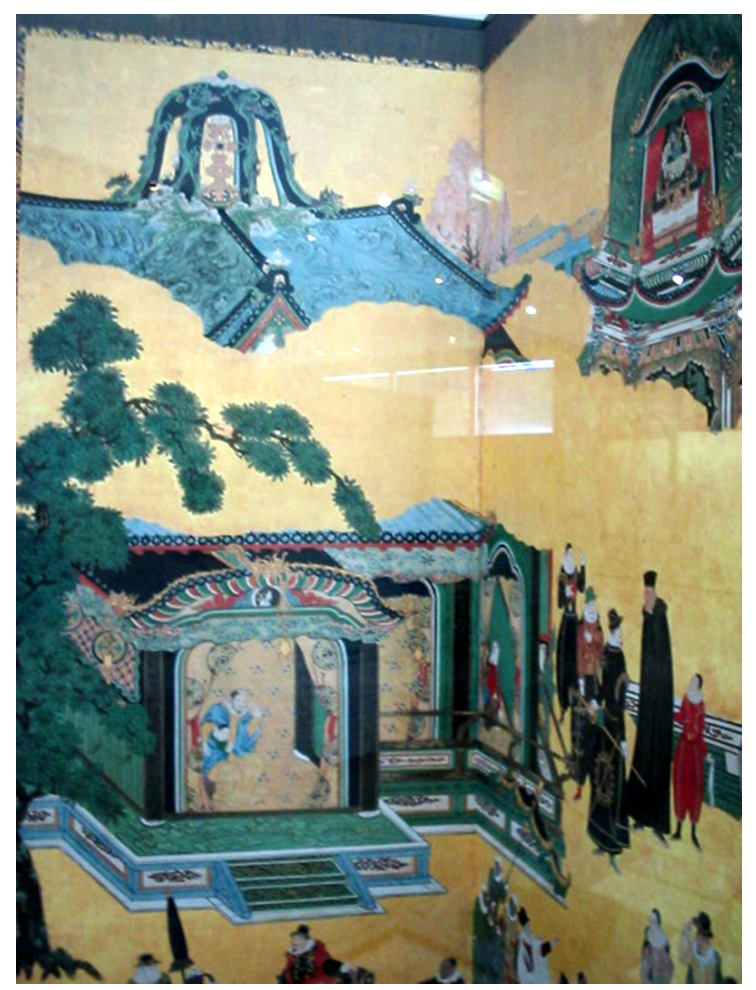

japonesas de impulsar las actividades comerciales desarrolladas por el gran navío conocido como "galeón de Macau", que representaba a grandes rasgos el conjunto de intercambios con China y el resto de Asia, mientras que al mismo tiempo, la Cristiandad alrededor de las áreas de Bungo y Hirado estaría protegida frente a los golpes adversos del destino, sean desastres naturales o persecuciones religiosas. Sin embargo, se trataba siempre de una soberanía compartida, puesto que los misioneros no deseaban administrar justicia y particularmente la pena de muerte, dentro de los dominios de Sumitada Dono大村 純忠; en este caso lo consideraban incompatible con la propagación de su fe.

Como es sabido, los europeos habían desdeñado y olvidado hacía tiempo sus propias tradiciones de geomancia y planificación de ciudades de acuerdo con el medio ambiente, lo que se venía a considerar en no pocas ocasiones como un hábito extraño y ligado al paganismo. El plano Renacentista tardío de la "ciudad ideal" era por tanto muy aplicado y difundido. En América y en Filipinas fueron las leyes de Indias, vagamente basadas en el tratadista Vitrubio, las que determinaron la forma de la mayoría de las ciudades. Cuando esto no era posible, como es el caso frecuente de India, China y Japón, se emprendieron desarrollos urbanos fortuitos que contenían al menos el conjunto de comodidades más habituales en Europa.

Sin embargo, se puede argumentar, como sostiene el filósofo Watsuji 和辻哲郎 que las condiciones climáticas en los territorios asiáticos eran opresivas y tropicales, muy alejadas del clima templado europeo ${ }^{6}$. Los nanban, habitantes emigrados (literalmente bárbaros del sur), no tenían un modelo sistemático a seguir para este tipo de condiciones y por lo tanto optaron por ciertos lugares comunes que eran más fáciles de regular. Además, los ibéricos no llegaron a estar familiarizados con los sistemas asiáticos de planeamiento y por otra parte el acceso generalizado a las ciudades más importantes estaba fuertemente restringido como evocan convincentemente nombres tales como "la ciudad prohibida" de Beijing y también la abandonada corte de Fatehpur Sikri cerca de Agra en India.

6 Watsuji (1961): 96. 


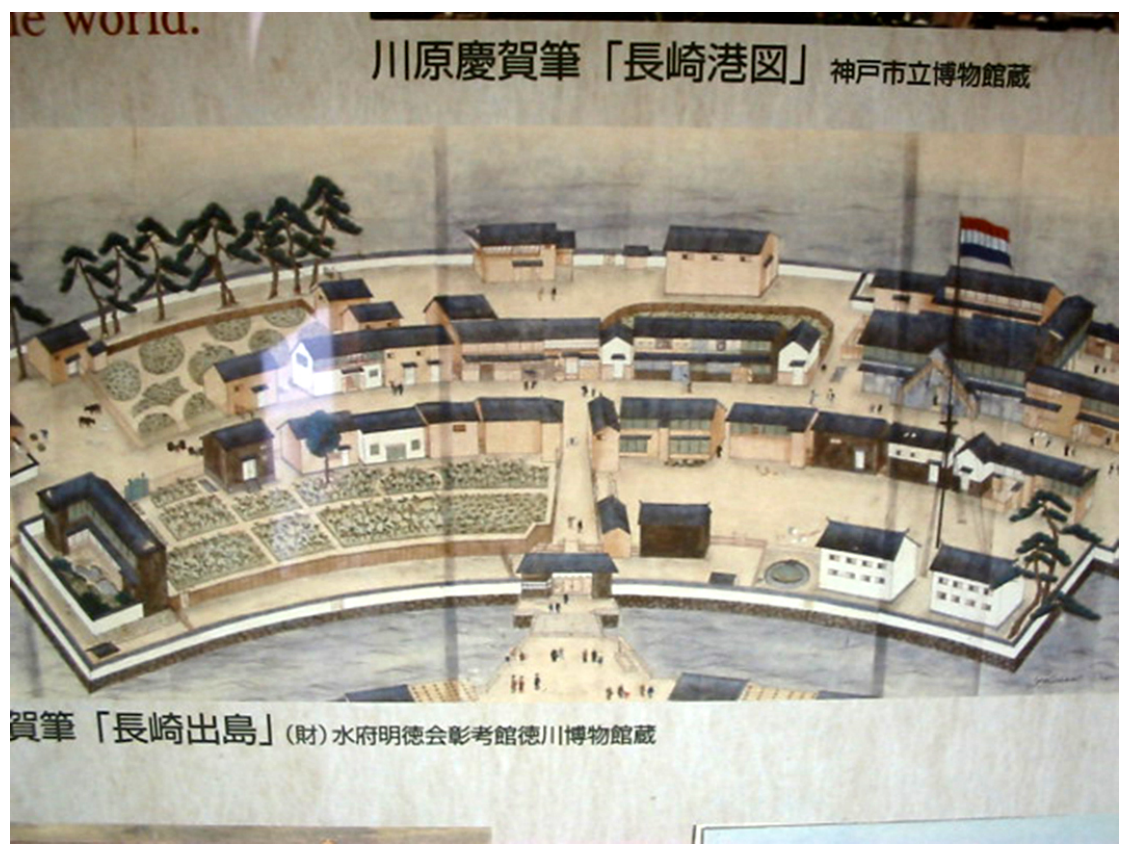

Fig.10. El minúsculo asentamiento holandés de Dejima. Fuente: Museo de Historia de Nagasaki

La conclusión más notable después de casi un siglo de relaciones complejas e inquietantes, fue un nuevo sentido de apertura hacia otras regiones del mundo, incluso dentro de Asia. El arte Nanban puede muy bien considerarse un fuerte testimonio avant la lettre de ello.

Este tipo de arte ofreció a los japoneses una visión del mundo que hasta entonces se pensaba que estaba comprendido dentro de los dominios de China, Siam y Japón. Los mapas de Blaeu y el gran Matteo Ricci que fueron transportados desde Europa y China por la misión de Kyûshû, remplazaron a los mapas conceptuales del estilo tradicional Gyogi, que eran más bien veredas o itinerarios. La exactitud de los mapas de estilo occidental era muy útil para la defensa y la administración. Estos mapas ponían a Europa en el centro y de ese modo ofrecían un nuevo "poder" como alternativa al modelo sino-céntrico. Además, incorporaban la incógnita de los vastos territorios americanos de los que tales imperios nunca habían tenido noticia.

Todo ello a su vez acrecentaba la formación de una identidad distinta contra la que medirse en una reevaluación del papel de China como representante del centro cultural del mundo. La palabra Zhongguo (China) 中国, quiere decir el imperio del centro, no tan diferente de la ciudad de Mediolanum en Italia septentrional (hoy Milano). Supuso pues lo anterior una forma alternativa de representación para las islas y las ciudades y con ello nuevos conceptos y costumbres que de alguna manera quedaron imbuidos dentro de la vida cotidiana. Las pinturas Nanban documentaban a veces sucesos en Kyûshû, la isla japonesa que se ubica más al suroeste, y por lo tanto resultaban informativas para el resto de Japón.

El arte Nanban se manifestaba de muchas formas diferentes. Comenzó con la importación de unas pocas pinturas religiosas en los estilos español y flamenco y después se inició una segunda oleada producida por los japoneses y los chinos siguiendo esos modelos, como en la escuela de pintura del seminario y conservatorio de Arima, en Macau con la espectacular fachada de la iglesia de Madre de Deus construida por los exiliados cristianos, o en el Jardín de la Cruz de Omura Sumitada (fig. 8).

Después de la embajada de Kyûshû, los artistas japoneses comenzaron a producir biombos representando la vida europea, las ciudades y los acontecimientos de Nagasaki. La idea de lo "occidental" era intrigante y exótica (ikokuchô 異国調). Muchos de estos objetos 


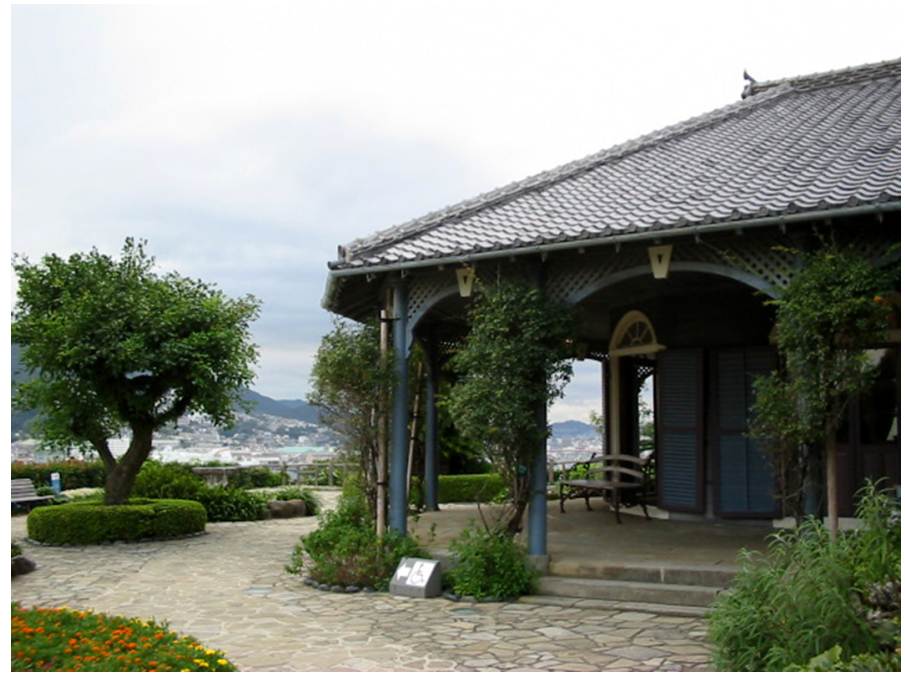

Fig. 11. La casa Glover en Nagasaki. Fuente: Joseph Cabeza-Lainez

resultaron populares y se manufacturaron para la exportación. Los biombos imaginarios que muestran iglesias y ciudades europeas o templos de estilo chino y asiático, ilustran el movimiento hacia una tentadora visión del mundo moderno (fig. 9). Se trataba del primer conato de un considerable despliegue de influencia extranjera que iba a dar forma al Japón que hoy día conocemos.

Como se ha mencionado, el encuentro Nanban presidió unas perspectivas totalmente nuevas y diferentes del mundo y de la vida urbana que pavimentaron el camino a expansiones urbanas futuras. Éstas se hicieron manifiestas por ejemplo cuando tuvo lugar apertura que superaba el anterior aislamiento o sakoku (鎖国) en tiempos de la Restauración Meiji.

La identidad exótica de Nagasaki no se perdió completamente, porque les fue permitido residir en una isleta llamada Dejima a los principales enemigos de los ibéricos, los holandeses; previa demostración de que solo buscaban el comercio y el conocimiento y en ningún caso la evangelización (fig. 10).

De su larga estancia de casi tres siglos da buena prueba la interesante figura del 蘭学者 Rangakusha, o estudioso de los modos y ciencias holandeses, que contribuyó en cierta medida a la modernización de la medicina, las ciencias y las técnicas en Japón, pero de modo sin duda insuficiente. Pues como también postulara Watsuji, el más fatal de los defectos del pueblo japonés radicaba, en una palabra, en su carencia de un modo científico de pensamiento. Este grave y extendido defecto de los japoneses no era según el autor algo que surgiera en un día ${ }^{7}$. Desde que dieron origen a la nueva ciencia, las naciones europeas habían pasado tres siglos permitiendo que este modo científico de pensamiento penetrase todos los aspectos de su forma de vida. Los japoneses, por el contrario, cerraron su país a las influencias extranjeras inmediatamente después del nacimiento de esta nueva ciencia. Y durante dos siglos y medio todas las facetas de ese espíritu moderno fueron clausuradas por la autoridad estatal. El rápido progreso de la ciencia durante estos doscientos cincuenta años permitió que la pérdida de Japón no pudiera remediarse con la subsiguiente importación acelerada de los frutos de tan formidable progreso científico.

En Nagasaki todo esto quedó expuesto bien a las claras: su cosmopolitismo e ideales de apertura permitieron que en ella se instalasen modernamente personajes como el escocés Thomas Glover, comerciante de armas y otros productos, quien construyó una villa homónima rodeada de amables jardines que hoy es patrimonio nacional (fig. 11). También destaca el escritor Pierre Loti, autor de tres novelas japonesas entre las que destacan, Les trois

${ }^{7}$ Watsuji (1961): 116. 


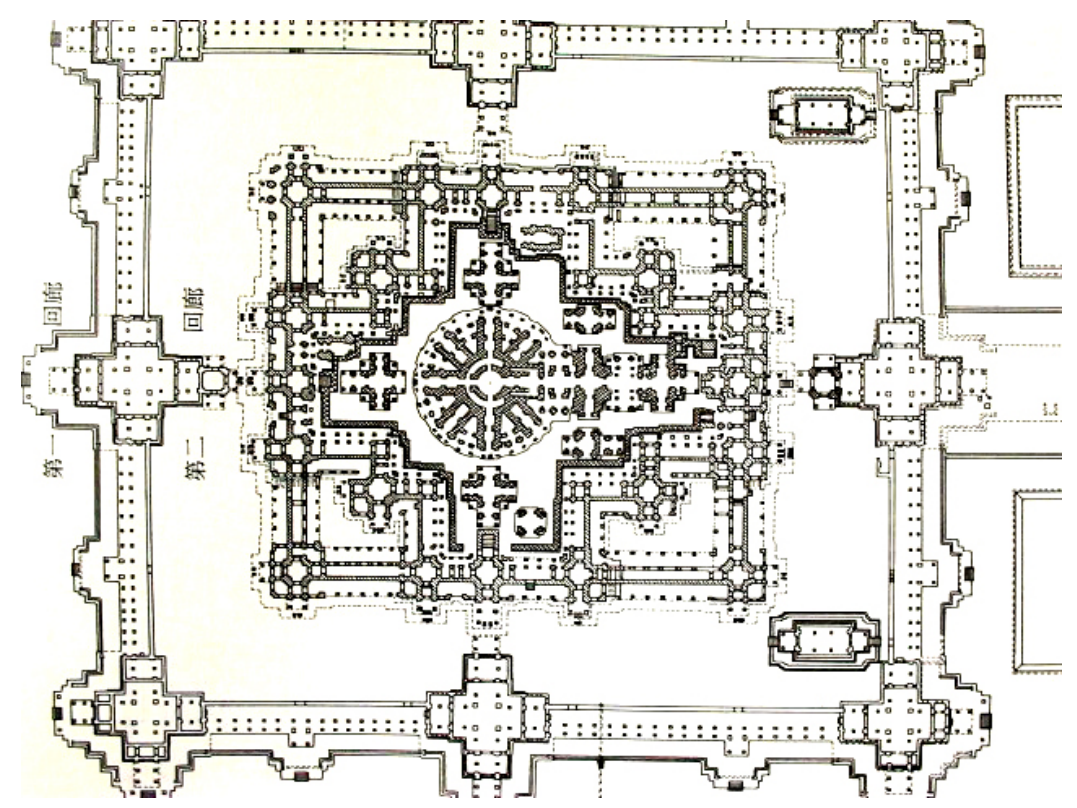

Fig 12. El complejo de Angkor Thom, copiado en planos por los comerciantes de del período Tokugawa en el SXVIII que se conservan en el museo de Mito (Ibaraki). Fuente: Cabeza Lainez, J. M. La Visión y la Voz: arte, ciudady cultura en Asia Oriental.

jeunesses de Madame Prune, y Madame Chrysanthème (que, como es sabido, resulta la base de la ópera Madame Butterfly de G. Puccini).

Loti, marino francés cuyo verdadero nombre era Julien Viaud fue compañero de navío de Paul Gauguin. Este último quedó más prendado de su primera novela exótica, Le Mariage de Rarahu, sobre la Polinesia, que de aquellas que tratan cuestiones propiamente japonesas. Resulta excitante especular sobre los resultados que se habrían dado en el arte contemporáneo de haberse producido una japonización de tan singular artista como la que le aconteciera a Vincent Van Gogh.

\section{Conclusiones}

El corolario provisional que nos explica en parte el hecho de que pervivan ciudades tan singulares como Nagasaki resulta ser que los "asentamientos extranjeros" ofrecían una plétora de comodidades y permitían cultivar la exportación de una imagen fascinante de Asia con productos muy bien conocidos y apreciados que constituían el arquetipo de lo "oriental" en el exterior. La narrativa también influye en ese fenómeno y un caso paradigmático son los personajes de las óperas de Puccini, Turandot o M. Butterfly, pues ya explicó la conocida artista Yoko Ono, que las mujeres orientales para Occidente, solo puede recaer en dos tipos, la sumisa hasta el extremo de la muerte Butterfly o la cortadora de cabezas Turandot, sin que existan trazas de un punto medio.

Junto con estos personajes, aires y costumbres exóticas, arribó una variada escenografía arquitectónica. Este escenario se separaba enormemente de las tradiciones ancestrales, pero era de algún modo vernáculo en el sentido de que había sido producido por una herencia asiática de diferente especie a la hasta entonces conocida.

En ese momento y no antes, se dio la rara circunstancia de que los valores "modernos" de las tradicionales "ciudades de fábula" de Asia tales como Angkor (fig. 12), Samarkanda o Vijayanagara en India, pero también urbes de influencias japonesas como Hoi-An, o chinas, Hue en Vietnam, llegaron a ser reconocidos y pudieron incorporarse al trabajo de urbanistas 
y arquitectos, destacando en el panorama japonés el arquitecto Chuta Ito. Estudiante en Londres, le preguntaron en qué consistía la arquitectura japonesa y como no pudo explicarlo adecuadamente, dedicó el resto de su vida a viajar por Asia documentándose incorporando sus hallazgos a la curiosa obra que nos legó.

En resumen, las influyentes colonias de extranjeros, que habían sido llevadas a escena desde el punto de vista cultural a través del anómalo episodio Nanban, permitieron en nuestra opinión, que se desarrollara un conjunto de hechos urbanos modernizados, que eventualmente constituían toda una red de influencias para los países asiáticos más desarrollados.

En ese sentido Japón debería considerarse como un ejemplo destacado. Las comodidades desplegadas en las áreas que se modernizaron aplacaban los prejuicios que normalmente se vienen atribuyendo a las concesiones extranjeras.

Sin embargo, aunque no sea materia de este artículo, no podemos obviar que los devenires político-estratégicos de los siglos XIX y XX en China y Japón, tiñeron de matices mucho más luctuosos lo que de otro modo bien podría haber resultado en un panorama idílico. En Nagasaki, la bomba de protones precisamente lanzada sobre el área "cristiana" habría de sellar definitivamente con su estela de muerte y destrucción, tan relevante papel para el imaginario del Mundo. 


\section{Bibliografía}

Bailey, G. A.: Art on the Jesuit Missions in Asia and Latin America. 1542-1773. Toronto: University of Toronto Press. (1999).

Beltrâo. R.: Retalhos. Macau: Livros do Oriente. (1990).

Bourdon, L.: La Compagnie de Jésus et le Japón (1547-1570). París: Fundaçâo Calouste Gulbenkian. (1993).

Cabeza Lainez, J.M".: "Geometry, Calculus and Cross-cultural influences on the anvil of Baroque Architecture". En: Arquitectura, diseño y sociedad en la temprana Edad Moderna. Madrid. Ed. Guido Cimadomo. Ediciones Asimétricas. (2019).

Cabeza Lainez, J.Mª: La Visión y la Voz: arte, ciudad y cultura en Asia Oriental. Córdoba: UCOPress Ediciones Universidad de Córdoba. (2018).

Cabeza Lainez, J.Ma.: "Semántica y Metafísica del Jardín Japonés”. En: El jardín japonés. Madrid: Tecnos -Grupo Anaya, Hachette Livre, (2015), pp. 228-240.

Cabeza Lainez, J.Ma .: "Estudio Introductorio". En: La Arquitectura del Orden Cósmico. (2011), pp. 2-23.

Cabeza Lainez, J.Mª ": "La Ciudad Japonesa: Ascenso y Declive de las Megalópolis". En: ¿Qué Es Japón? Introducción a la Cultura Japonesa. Cáceres: Universidad de Extremadura, Servicio de Publicaciones, (2009), pp.187-216.

Cabeza Lainez, J.Ma .:"Desde Sri Lanka Hasta Japón: Ideas Acerca de la Evolución del Stupa”. En: Colección Española de Investigación Sobre Asia Pacifico (Ceiap). Granada: Universidad de Granada, (2007), pp.553-569.

Cabeza Lainez, J.M .: "Ernest Francisco Fenollosa and the Quest for Japan". En: Bulletin of Portuguese - Japanese Studies. 9, (2005), pp.75-99

Cabezas, A.: El Siglo Ibérico de Japón. La presencia hispano-portuguesa en Japón (1543-1643). Valladolid: Publicaciones de la Universidad de Valladolid. (1994).

Couto, D. Da Asia de Diogo do Couto (1778): Dos Feitos que os Portugueses Fizeram na Conquista e Descubrimento das Terras, e Mares do Oriente. Lisboa. Ed. Facsímil (1973).

Fróis, L.: Traité de Luís Fróis, S.J. (1585) sur les contradictions de moeurs entre Européens et Japonais [French Edition]. París: Editions Chandeigne. (1993).

Gobierno de la Prefectura de Nagasaki: Sitios Cristianos Ocultos en la Región de Nagasaki. División del Patrimonio Mundial. (2018).

He,C., Zeng, Z. Yuan MingYuan Lin Yi Shu: 何重义, 曾昭奋 圆明园林艺术 (El Método Artístico en los jardines del Yuan Ming Yuan). Beijing: Publicaciones Científicas.

Hesselink, R. H. (2015) 'I Go Shopping in Christian Nagasaki: Entries from the Diary of a Mito Samurai, Ōwada Shigekiyo (1593)', Bulletin of Portuguese - Japanese Studies, (1593), (1995), pp. 27-45.

Huang, S. Gong. Y.: Li Madou Shijie Ditu Yanjiu. 利玛窦世界地图研究.上海古籍出版社. 黄時鍳, 龚缨晏. (Investigación sobre los mapamundis de Matteo Ricci). Shangai: Publicaciones de Objetos Antiguos de Shangai. (2004).

Kaulācāra, Rāmacandra: Śilpa Prakāsa: Medieval Orissan Sanskrit Text on Temple Architecture. SSanskrit Text and English Version]. Leiden: Brill. (1966).

Kircher, A.: China Monumentis. Amsterdam. Bibliothèque National de France. Paris. (1667).

Kircher, A. Turris Babel. Amsterdam. Bibliothèque National de France, (1679).

Lefevre, H.: The production of Space. Nueva Jersey: Blackwell Publishers. (1991).

Lucena, J.: História da Vida do Padre Francisco de Xavier. Lisboa: Publicaçôes Alfa. (1989).

Lyp, E.: Feng Shui. Environments of Power.Londres: A. D. Academy Editions. (1994).

Martínez Shaw, C. (Ed.).:El Pacífico Español. De Magallanes a Malaspina. Ministerio de Asuntos Exteriores-Universidad de Barcelona. (1988).

Matsuda, K.: The relations between Portugal and Japan. Lisboa: Junta de Investigações do Ultramar e Centro de Estudos Históricos Ultramarinos. (1965).

Pacheco, D.: "The Founding of the Port of Nagasaki and its Cession to the Society of Jesus Port of Nagasaki”, Monumenta Nipponica, 25(3/4), (1970), pp. 303-323. 
Pacheco, D.: 'El primer mapa de Nagasaki.', Boletin de la Asociación Española de Orientalistas, 7, (1971), pp. 11-29.

Pintado, M. A.: Stroll through Ancient Malacca. Macau: Instituto Cultural de Macau. (1990).

Sola, E.: Historia de un desencuentro. España y Japón. 1580-1614. Alcalá: Fugaz Ediciones. (1999). Spence, J.: The Memory Palace of Mateo Ricci. New York:Viking. (1984).

Shōnagon, S.: The Pillow Book of Sei Shōnagon [trad. Ivan Morris]. Londres: Penguin Books. (1971).

Valladares, R.: Castilla y Portugal en Asia (1580-1680). Lovaina: Leuven University Press. (2001).

Vu Thanh, H.: “À la frontière de l'Europe et de l'Asie? Le cas de Nagasaki aux XVIe-XVIIe siècles". En e-Spania, (30), (2018), pp. 0-15. doi: 10.4000/e-spania.28109

Watsuij, T.: Climate and Culture: A Philosophical Study trad. Geoffrey Bownas] Westport, CT: Greenwood Press. (1961). 